\title{
Reading for Both Learning and Enjoyment---- The Application of Flipped Classroom in College English Extensive Reading Course
}

\author{
ChanjuanChen ${ }^{1, a}$, FanHu $^{2, b}$ \\ ${ }^{1}$ Xianda College of Economics \& Humanities Shanghai International Studies University, \\ Shanghai, China \\ ${ }^{2}$ Shanghai University of Medicine \& Health Sciences, Shanghai, China \\ accjcynthia@hotmail.com, bjoyking2003@163.com
}

Key Words: Flipped Classroom, Extensive Reading, College Language Education

Abstract.In terms of ineffectiveness and inconsistency of current college English extensive reading course, it is high time that instructors searched for a more creative and innovative approach to take the place of conventional teaching method. Flipped classroom teachingmode avoids disadvantages of traditional teacher-centered lecture and adopts active in-class tasks and pre-/post-class assignments. In this paper, the author gives a detailed account of the flipped classroom, and attempts to characterize it with its theoreticalfundamentals, which account for the feasibility of this new method in extensive reading course in particular. The author constructs a theoretical argument that flipped approaches might stimulate students' interest in reading in and out of the class as well as improving the process of teaching and learning. Meanwhile, the paper lists some unavoidable challenges from the perspective of teachers and students, which lead to further research in this field.

\section{Introduction}

Extensive reading is a way of language learning through a considerable amount of reading and is of great importance in college curriculum for English majors.Reading can enhance students' encounter with unknown words and phrases and help to cultivate their ability to infer the meaning from the context without consulting any dictionaries, thus enlarging their vocabulary and broadening their horizons in the long run. Besides, a great deal of reading input is definitely beneficial to student's fluency development. As a result, the significance of extensive reading course is self-evident.

Firstly, the problems in current extensive reading course are supposed to are commonplace. When it comes to the course itself, every week it only lasts 90 minutes, and each semester students have 16 sessions in all, which is far from enough for them to improve reading achievements. Time constraint seemingly is a large barrier to the course coverage and interactions between instructors and students. The reading materials are not only monotonous but also out of date, as contents of texts do not keep pace with the times. In addition, the texts are rather elusive, but the following exercisers are comparatively easy because sometimes students can finish them even without reading the texts at all, which indicates the noticeable disadvantages of the textbooks. On the other hand, a great number of students have not formed a good habit of reading extensively, and a large proportion of students even do not read a single book each year. It is not uncommon that undergraduates read quite slowly with a small vocabulary, and regressions occur so often that they are not able to have a correct and rapid understanding of the context, thereby giving rise to the loss of joy in the course of reading. Teachers usually employ the traditional teaching methods such as grammar-translation and sometimes spoon-feed students with a lot of new words and expressions and force them to memorize without any context. The conventional teacher-centered class instruction hinders the fulfillment of self-motivation and initiative, which, to some extent, discourages students from learning on their own and reduces reading efficiency.In practical terms, students always complain that they do rather poorly in the section of reading comprehension in an examination, which eventually influences their general mark.

Driven by professional dissatisfaction with the existing teaching materials and methods, and 
increasingly by the imperatives of development of students' reading comprehension, questions concerning the design, implementation, supervision and improvement of language teaching, are, more than ever before, of vital concern to teachers and researchers. The traditional lecture format seems to be less appealing to the learners. It is apparent that a great many researcheshave been conducted as to the innovation and reform of language education and in recent years flipped classrooms are prevalent among language teaching. This paper closely examines the application of flipped classroom model in the extensive reading courses for English majors in the college.

\section{Flipped Classroom Teaching Mode}

Flipped Classroom is a positive learning, which lessens anxiety of students and enhances learning proficiency. There is a great deal of evidence that this new method has positive impacts on students' involvement in language learning.

1.The Definition of Flipped Classroom.According to Andrews, Leonard, Colgrove and Kalinowski (2011), many of the learning difficulties experienced by students in undergraduate courses can be attributed to the passive role played by them during traditional lectures; they advocate for active learning as a remedy. One such learning environment that enables students to engage in active learning is the flipped classroom approach (Berret, 2012; Milman, 2012). In wikipedia's definition, "flipped classroom is an instructional strategy and a type of blended learning that reverses the traditional learning environment by delivering instructional content, often online, outside of the classroom. It moves activities, including those that may have traditionally been considered homework, into the classroom. In a flipped classroom, students watch online lectures, collaborate in online discussions, or carry out research at home and engage in concepts in the classroom with the guidance of a mentor. "When students have dominance over what and how they learn, the learning belongs to them. Teachers become guides rather than dispensers of information, and students become active learners instead of passive receivers of facts. In the traditional "chalk-and-talk" classroom instruction, teachers play the role of diffusing knowledge, and accordingly learners passively receive the information with less interest in the course itself. Nevertheless, in the flipped classroom mode, the responsibility of learning is shifted from the instructors to the learners. And in-class instructions consist of explanation of the contents in great depth and meaningful interactions and opportunities of learning, which gives full play to classroom performance and efficiency.

2.Theoretical Features in Flipped Classroom Mode.In the first place, the proliferation of access to the Internet amounts to the prerequisites for the successful implementation of flipped classroom mode. The main function of information technology is to record contents in conventional classes and transferred to after-class activities via the Internet, which is the first step for flipped classroom and lays a foundation for the rearrangement of class time and enhancement of learning efficiency. Secondly, time is a fundamental element in classroom teaching activity and a crucial factor in teaching effect and learning efficiency. However, reforms in classroom teaching devote a lot to the innovation of contents and methods, yet attach little to the disadvantage of time limits in class. One of the major features of flipped classroom mode is the exchange of "in-class activities" for "post-class activities", which demonstrates the transfer of center in the classroom education. The instruction of teachers is transferred to be completed after class and each student can maximize the time in class according to their own learning habit and style. Evidently, team-work learning, collaborative learning, and investigative learning become the focus in the flipped classrooms. Additionally, mechanism of interaction between instructors and students is strengthened. In the instructional "teacher-centered" class mode, students' role is usually overlooked. On the contrary, the inverted class mode places much emphasis on the leading position of students, when teachers serve as observers and guides and get ready to help them out by discussing with them to tackle the problems together. Teachers give more illustrations, if necessary, to the whole class. With the 
increase in the opportunity of face-to-face communication, teachers have more access to one-to-one guidance and help to dispel students' doubts and finally relieve their pressure. In other words, more communications enable teachers to have a better understanding of students' learning level and give them helping hand specifically. Peer instructions in the form of cooperation have a positive influence on their learning process. Consequently, learners construct knowledge framework and collaborate with others to accomplish in-class and post-class activities. Students can choose the place and time of study based on their own demands. They don't need to spend much time on what they've already known, but they can allocate their time more reasonably. The flipped classroom is the gateway to the learning environment of effective participation and engagement and the strengthening of application of knowledge, thus cultivating their awareness of concept of life-long learning.

3.The Feasibility of Flipped Classroom Mode in Language Teaching.To begin with, currently, college courses adopt multimedia aided teaching and teachers use PPT and videos to diffuse information, but students can't have a good command of knowledge on account of cognitive overload in each session so that they cannot internalize knowledge in short time. As a result, it's vital that teachers should make effective use of multimedia and personalize study mode for students. There's no doubt that college teachers are well-educated and receptive to new ideas and they strive to improve their teaching methods to optimize the effects. Moreover, they are familiar with information technology, therefore they can take full advantage of the Internet to search for information and make microlectures or PowerPoint, which ensures the successful implementation of flipped classroom in technical respect. Furthermore, college students are bored with the tedious instructional class mode in senior high schools, so they welcome this new and innovative teaching mode with both arms. Since they are capable enough to learn by themselves after class, it's not impractical for them to study independently or cooperatively in post-class activities. And their command of English grammar and vocabulary allow them to communication smoothly with the help of some gestures and even their mother tongue.

\section{The Practical Perspective of Flipped Classroom Mode}

Given theoretical basics and characteristics of flipped classroom, the application of this approach in language teaching is accordingly feasible. And in the following parts, the practical aspects will be depicted in detail.

\section{The Application of Flipped Classroom Mode}

In most cases, one week is devoted to each lesson of one certain topic. Students are expected to read the texts in advance or watch the lectures in various formats. Microlectures, which present traditional course material in a videotaped way, are nearly accessible to every student since the widespread use of the Internet in the globe. Teachers request learners to watch the videotapes online and finish all the questions independently or through the group work. Alternatively, lectures in PowerPoint with sounds contain the same materials as the traditional courses in accordance with the concrete teaching objectives, which can be downloaded and studied repeatedly for the convenience of students.

Students are expected to come to the class with full preparation for the relevant study materials. In order to achieve knowledge internalization, a variety of classroom activities can be carried out. For instance, students are selected at random to demonstrate what they have learned beforehand and problems they may encounter during the pre-class study. On the one hand, instructors can evaluate the preview achievements, and students are able to, on the other hand, improve their oral performance by practice. Then the teacher concludes the questions put forward by the students and organize students to discuss them in class. Firstly, students are divided into several groups and a group leader is chosen in each group. Each member in the group is assigned different tasks, shares and exchanges information and eventually reaches a consensus. Students cooperate and 
communicate with team members; hence their capability of critical thinking is improved. Students are requested to display their presentation in such forms as PPT or dialogues in order to exchange their findings with other team members and then students reconstruct knowledge framework. In other words, students' potential can be fully fulfilled. Admittedly, some problems still can't be addressed even with the exchange of information by students. Teachers come to their rescue by helping them have a full glimpse of contents. Ultimately, exploration activities after class are indispensable in order to cultivate their ability to solve some practical problems. Learners draw their own conclusions on the basis of what they've acquired by means of searching on the Internet. Students can get a brief understanding of scientific research methodology. Inverted class mode enables teachers to have a relatively objective and systematic evaluation of students based on their performance in the pre-, in-, and post- class activities respectively, which does good to the improvement of their teaching methods.

\section{The Application of Flipped Classroom Mode in College English Extensive Reading Course}

Firstly, proper textbooks should be selected with specific aims. Taking the characteristics of flipped classrooms into consideration, teachers choose the passages which are of average length, because too lengthy texts exert a negative influence on learners and make it difficult to conduct activities in the class. In addition, texts ought to keep pace with the times and evoke students' interest, which includes information of all sorts. As to the design of pre-class activities, short videos are made complying with the objectives of this session as well as reading techniques and methods. The about-15-minute video, as a rule, includes illustration of key language points, new words and expressions, analysis of sentence structure and interpretation of some long sentences. After reading texts and watching pertinent videos, students have a rough idea of the content on their own, with the help of the Internet or by communicating with classmates and conclude what are still beyond their understanding. The autonomous preparation for the class ensures the implementation of the following in-class activities.

Secondly, in-class activities are of the same importance in the flipped classroom mode. The collection, analysis and comment of information are even more important than the literal understanding of texts. For example, students are required to write down specific details relevant to the theme, or draw a picture to illustrate the complex relations among main characters. Teachers ask students to make a discussion concerning the words, structure, and theme and associate them with what they've acquired in the previous sessions. And students can have instant feedback from teachers with their timely remarks on their classroom performance. Alternatively, students may be requested to read chosen paragraphs in a cooperative way within a small group, which enables them to get to know other students' analytical way and benefit a great deal from others by means of mutual learning. To put it briefly, students should be encouraged to take an active part in a wide variety of activities.

\section{The Challenges for Clipped Classroom Mode}

As is known to all, clipped classroom is a comparatively new teaching mode which is unfamiliar to students. Perhaps students have to spend lots of time accommodating themselves to this teaching approach. Students must spend much time completing the preview section before they come to class, which makes some students think that teachers make extra assignments for them and the preparation for pre-class activities take up much of their leisure time. As a consequence, students are supposed to get themselves accustomed to the new learning mode with the help of the Internet, their peers and teachers. On the other hand, it takes teachers a tremendous amount of time to design and make pre-class and post-class activities with a view to tapping students' potential and arousing their interest in the course. Much time and effort are devoted to the preparation for the course, which poses great challenges for teachers themselves and, to a certain degree, constitutes heavy burden on them. What's more, since students come to class with questions, teachers are responsible for helping 
learners to work them out, which calls for the fact that teachers are armed with a great deal of specialized knowledge and are adept at guiding students.

\section{Summary}

In the flipped classroom, students are able to take control of their own learning pace, and responsible for their own learning process, which is quite distinct from conventional teaching approach. Drawbacks still exist in this new teaching method, and therefore teachers should endeavor to maximize its positive effect and minimize its detrimental impact as well. I am fully convinced that this nonconventional teaching approach is helpful promoting a more interactive teaching style and doesgood to college English extensive reading course.

\section{References}

[1]Abeysekera, Lakmal, and Phillip Dawson (2015). "Motivation and cognitive load in the flipped classroom: definition, rationale and a call for research." Higher Education Research \& Development 34(1), 1-14.[J]

[2] Alvarez, B. (2011). "Flipping the classroom: Homework in class, lessons at home". Education Digest: Essential Readings Condensed For Quick Review, 77 (8): 18-21.[J]

[3] Andrews, T., Leonard, M., Colgrove, C., \& Kalinowski, S. (2011). Active learning not associated with student learning in a random sample of college biology courses. Life Sciences Education, 10(4), 394-405. [J]

[4] Berrett, D. (2012, February 19th). How 'flipping' the classroom can improve the traditional lecture. The Chronicle of Higher Education.[J]

[5] King, Alison. "From sage on the stage to guide on the side."College teaching 41 1: 30-35. [J]

[6] Marco Ronchetti (June 2010), "Using video lectures to make teaching more interactive", International Journal of Emerging Technologies in Learning (iJET)[J]

[7] Maureen Lage, Glenn Platt, Michael Treglia (2000), Inverting the Classroom: A gateway to Creating an Inclusive Learning Environment, Journal of Economic Education.[J] 